\title{
Spatial and temporal distributions of $b$-value in and around Shinmoe-dake, Kirishima volcano, Japan
}

\author{
Keita Chiba* (10) and Hiroshi Shimizu
}

\begin{abstract}
Kirishima Shinmoe-dake, located in southern Kyushu, Japan, erupted in October 2017 after 6 years of quiescence. Analysis of volcanic gas indicates that magma upwelling from depth affected this eruption. Shinmoe-dake's recent eruptive history also includes phreatic eruptions in 2008 and 2010 and a magmatic eruption in 2011. We examined spatial and temporal variations in $b$-values to investigate the magma plumbing system in and around Shinmoe-dake and its possible effects on unrest. A region with relatively high $b$-values $(b=1.5)$ is located at depths of -1.0 to $2.0 \mathrm{~km}$ below sea level beneath the summit. It is likely that this anomalous region was generated by crustal heterogeneity, as it colocates to pressure sources. We investigated temporal variations in b-values from January 2007 to October 2017 in two regions: beneath the summit and 7.0-8.0 km northwest of the summit; the latter corresponds to the region above the locations of pressure sources related to the 2011 and 2017 eruptions. An increase in the $b$-value $(b=1.4)$ beneath the summit was observed beginning in early 2009, followed by a subsequent decrease $(b=0.9)$ immediately before and during the 2011 eruption. Similar temporal changes in the $b$-value were also observed beneath the summit before the 2017 eruption. From these results, we can infer that the increase and subsequent decrease in $b$-value express the activation of small cracks, due to the generation of hydrothermal fluids, and the development of cracks, which produces higher magnitude earthquakes, respectively. Meanwhile, a decrease in $b$-value $(b=0.6)$ was observed in the region northwest of the summit during the 2011 and 2017 eruptions. Thus, it is possible that the decreases in $b$-value in this region result from the activation of small cracks and the development of these crack systems and/or a change in the stress field near the magma chamber, which produce higher magnitude earthquakes.
\end{abstract}

Keywords: $b$-value, Crustal deformation, Crustal heterogeneity, Stress field, Magma chamber, Shinmoe-dake volcano

\section{Introduction}

Shinmoe-dake is one of the most active volcanos of the Kirishima volcano group, a cluster of 20 volcanoes in southern Kyushu, Japan (Imura and Kobayashi 1991). Relatively large historic eruptions have occurred at Shinmoe-dake, including a Plinian eruption in 2011 (Japan Meteorological Agency: JMA). The source magma chamber of the 2011 eruption was located at depths below $8.0 \mathrm{~km}$, approximately $7.0-8.0 \mathrm{~km}$ northwest of the summit, as inferred from an analysis of crustal deformation (e.g., Nakao et al. 2013; Ueda et al. 2013) and resistivity

*Correspondence: kchiba@sevo.kyushu-u.ac.jp

Faculty of Science, Institute of Seismology and Volcanology, Kyushu

University, 744 Motooka, Nishi-Ku, Fukuoka 819-0395, Japan structure (Aizawa et al. 2013). After a quiescent period of 6 years, Shinmoe-dake erupted from October 11, 2017, to October 17, 2017 (JMA 2017). Analysis of volcanic gas suggests that magma upwelling from depth affected this eruption (AIST 2017). In addition to the 2011 and 2017 eruptions, small phreatic eruptions occurred at Shinmoedake in 2008 and 2010 (JMA). Understanding volcanic activity and the magma plumbing system, in and around Shinmoe-dake, is therefore important to accurately assess the volcano's potential for unrest. In this study, we examined spatial and temporal variations in $b$-values of volcano-tectonic (VT) earthquakes to better understand eruptive activity and to investigate the magma plumbing system in and around Shinmoe-dake. 
Earthquake frequency-magnitude distributions were first developed in Japan by Ishimoto and Iida (1939). Subsequently, Gutenberg and Richter (1944) introduced the frequency-magnitude distribution (FMD):

$$
\log N=a-b M,
$$

where $N$ is the cumulative number of earthquakes with magnitudes $\geq M$ and $a$ and $b$ are constant coefficients. The coefficient $b$ in (1) is called the $b$-value. The $b$-value depends on various factors, such as the applied shear stress or effective stress (e.g., Scholz 1968; Wyss 1973; Urbancic et al. 1992), material heterogeneity (Mogi 1962), and the temperature gradient (Warren and Latham 1970). Computed $b$-values are often higher for volcanic areas than for typical tectonic earthquake sequences (e.g., Frohlich and Davis 1993; Wyss et al. 1997; McNutt 2005). Many studies have demonstrated the effectiveness of calculating the spatial and temporal distributions of $b$-values in interpreting volcanic structure (e.g., Wiemer and Benoit 1996; Wiemer and McNutt 1997; Wiemer et al. 1998; McNutt 2005; Bridges and Gao 2006; Farrell and Smith 2009). We therefore anticipate that a detailed image of the magma plumbing system can be obtained in and around Shinmoe-dake based on a spatiotemporal analysis of the $b$-value, as a dense network of permanent seismic stations exists on and around the volcano.

\section{Data and methods}

From the volcanic earthquake catalog constructed for the region of Kirishima volcano by JMA, we used only VT earthquakes in this study, which consist of A-type (with a distinct $\mathrm{P}$-wave onset occurred near volcanoes) and $\mathrm{BH}$ type events (with an unclear phase with relatively high frequency), according to the classification by JMA data file format. This catalog totally consists of 30 seismic stations, including 13 operated by the JMA, 11 operated by the Earthquake Research Institute of the University of Tokyo (ERI), 5 by the National Research Institute for Earth Science and Disaster Resilience (NIED), and 1 by Kagoshima University (Fig. 1). The original VT events for this study were recorded from August 1, 2002, to October 26, 2017; the total number of catalog VT events in this time window is 4569 . The hypocentral depths are calculated with respect to sea level. Mean hypocentral errors in the horizontal direction, vertical direction, and origin time were $0.549,0.585 \mathrm{~km}$, and $0.146 \mathrm{~s}$, respectively. We used the ZMAP software package (Wiemer 2001) for maximum likelihood $b$-value calculations. As a preliminary step, it is necessary to manually inspect calculated catalog $b$-values, to determine whether the observed FMD can be described by a power law. The catalog completeness magnitude $M_{\mathrm{c}}$, which is the lowest magnitude that satisfies the FMD, was calculated using the goodness-of-fit methods of Wiemer and Wyss (2000) and Wiemer and Wyss (2002). The latter study defined the $90 \%$ goodness-of-fit level as $M_{c}$, which implies that $90 \%$ of the variability in the observed FMD can be explained by a synthetic power law. However, volcanic catalogs do not necessarily reach this level, mainly due to the relatively small number of events and bimodal frequency-magnitude distributions caused by volcanic earthquakes swarms. For example, Bridges and Gao (2006) adopted a goodness-of-fit level of $74 \%$ as an empirical threshold for catalog data in calculating the $b$-value beneath Makushin Volcano, Unalaska Island, Alaska, USA. It was found that fitting a power law could explain $82-83 \%$ of the variability with an $M_{c}$ value of -0.6 to -0.4 in this study, which are the maximum values in the fitting test. In addition to the need to select events whose FMD can be described by a power law, we also evaluated the effects of changes in network coverage due to station additions and failures. The catalog data generally consist of events that have been precisely located in and around Shinmoe-dake since 2002; the average number of observations per event is 10. Furthermore, artificial changes in seismic detection rates have not been found since 2002 (Additional file 1: Figure S1). We also calculated temporal changes of $M_{\mathrm{c}}$ in overlapping 500-event windows shifted by 20 events per time step, using the original catalog data. As a result, a decrease in $M_{\mathrm{c}}$ has not been seen since 2007, despite the addition of new stations (Additional file 1: Figure S2). We therefore treat the JMA catalog in and around Shinmoe-dake as having precise locations and static network coverage. From the above, based on temporal variations in $M_{\mathrm{c}}$, we selected 2541 events with $M_{J}$ (JMA magnitude) $\geq-0.5$ that occurred between January 1 , 2007, and October 26, 2017 (Fig. 1). Spatial distributions of $b$-value were estimated using a grid technique with $0.3 \mathrm{~km}$ horizontal and $0.5 \mathrm{~km}$ vertical spacing. A total of 50-100 events were sampled within a sphere centered at each grid point. For each grid, the volume of the sampling sphere is inversely proportional to the density of earthquake hypocenters in the vicinity of the grid point; the maximum sampling radius allowed was $3.5 \mathrm{~km}$. For each grid point, a $b$-value was then estimated using the maximum likelihood method of Aki (1965):

$$
b=\log e /\left(M_{\text {mean }}-M_{0}\right),
$$

where $M_{\text {mean }}$ is the mean magnitude and $M_{0}=M_{c}-0.05$ for magnitude bins with uniform widths of 0.1. Temporal changes in $b$-values were calculated in overlapping 50 -event windows shifted by 10 events per time step.

\section{Results}

Three-dimensional $b$-value distributions are shown in Fig. 2. If less than 50 events were located within $3.5 \mathrm{~km}$ of a grid point, the corresponding $b$-values were not 


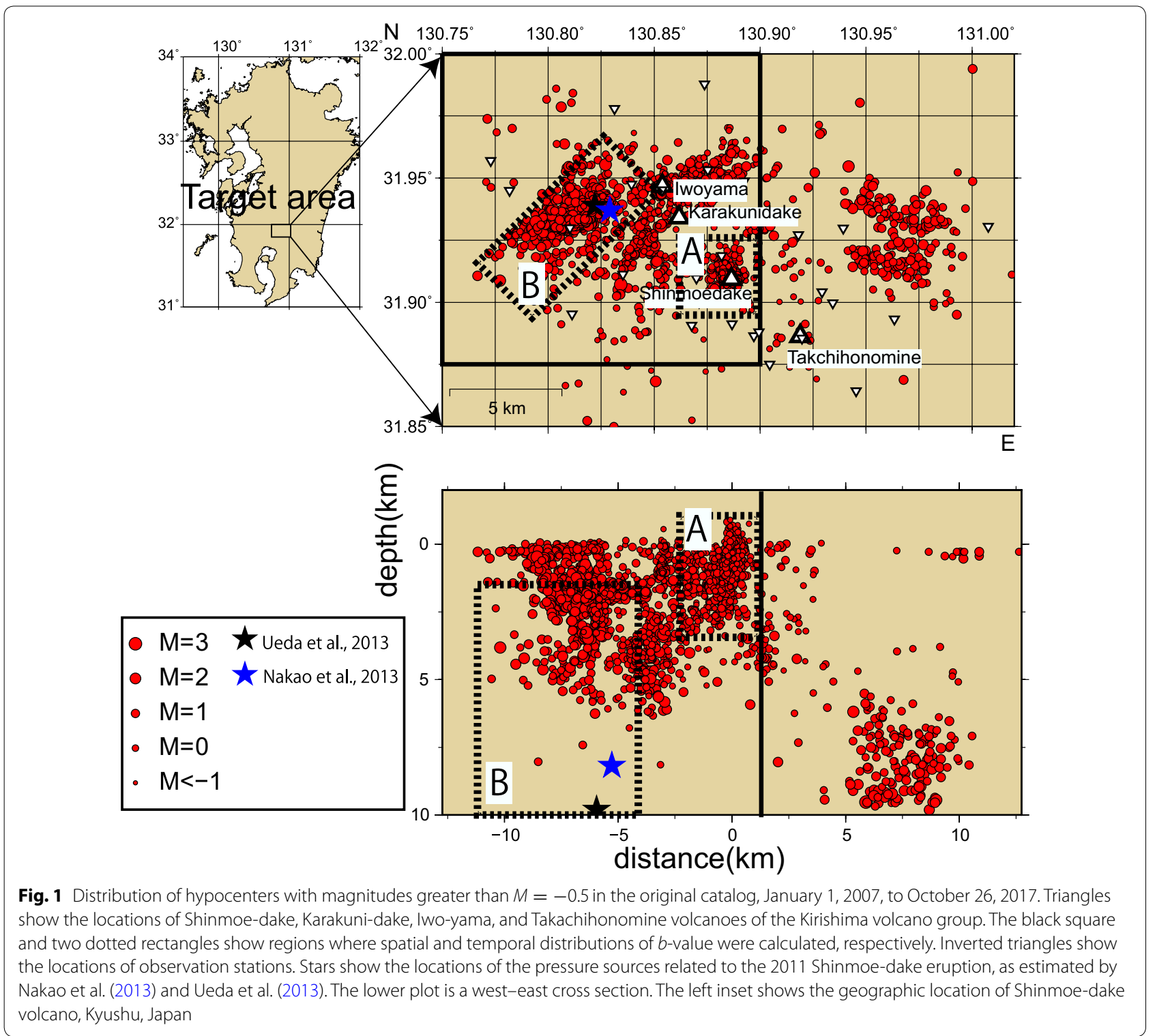

mapped on the grid. As a result, we found that a region with relatively high $b$-value $(b=1.5)$ is located at depths of -1.0 to $2.0 \mathrm{~km}$ beneath the summit (Fig. $2 \mathrm{a}-\mathrm{c}$ ). We quantitatively evaluated the heterogeneities of the $b$-values using the $p$ test (Utsu 1992), for which the $p$ value is defined by

$$
p=e^{(-\mathrm{d} A / 2-2)},
$$

where $\mathrm{d} A=-2 N \ln (N)+2 N_{1} \ln \left(N_{1}+N_{2} b_{1} / b_{2}\right)+2 N_{2}$ $\ln \left(N_{1} b_{2} / b_{1}+N_{2}\right), N_{1}$ and $N_{2}$ are the numbers of events within the volumes to be compared, and $N=N_{1}+N_{2}$. Because the $p$ value represents the probability that two areas have the same $b$-value, a pair of $b$-values can be considered distinguishable if the $p$ value obtained from the pair is small. Using Eq. (3), we evaluated the heterogeneous states of $b$-values in the two circled regions in Fig. $2 \mathrm{~b}$ with fixed event numbers $\left(N_{1}=N_{2}=100\right)$. For the anomalous area (labeled I in Fig. 2b) and the background area (II in Fig. 2b), the resulting values $b_{\mathrm{I}}$ and $b_{\mathrm{II}}$ are 1.29 and 0.85 , respectively. These $b$-values yield a value of $p=0.004$; i.e., the probability that these regions of relatively high and middle-low (background) $b$-values have the same true $b$-values can be rejected at the $99.6 \%$ confidence level.

Next, we investigated temporal variations in $b$-values using hypocenters distributed in and around Shinmoedake. Many events have occurred beneath the summit, as shown in Fig. 1; however, in addition, JMA (2017) 

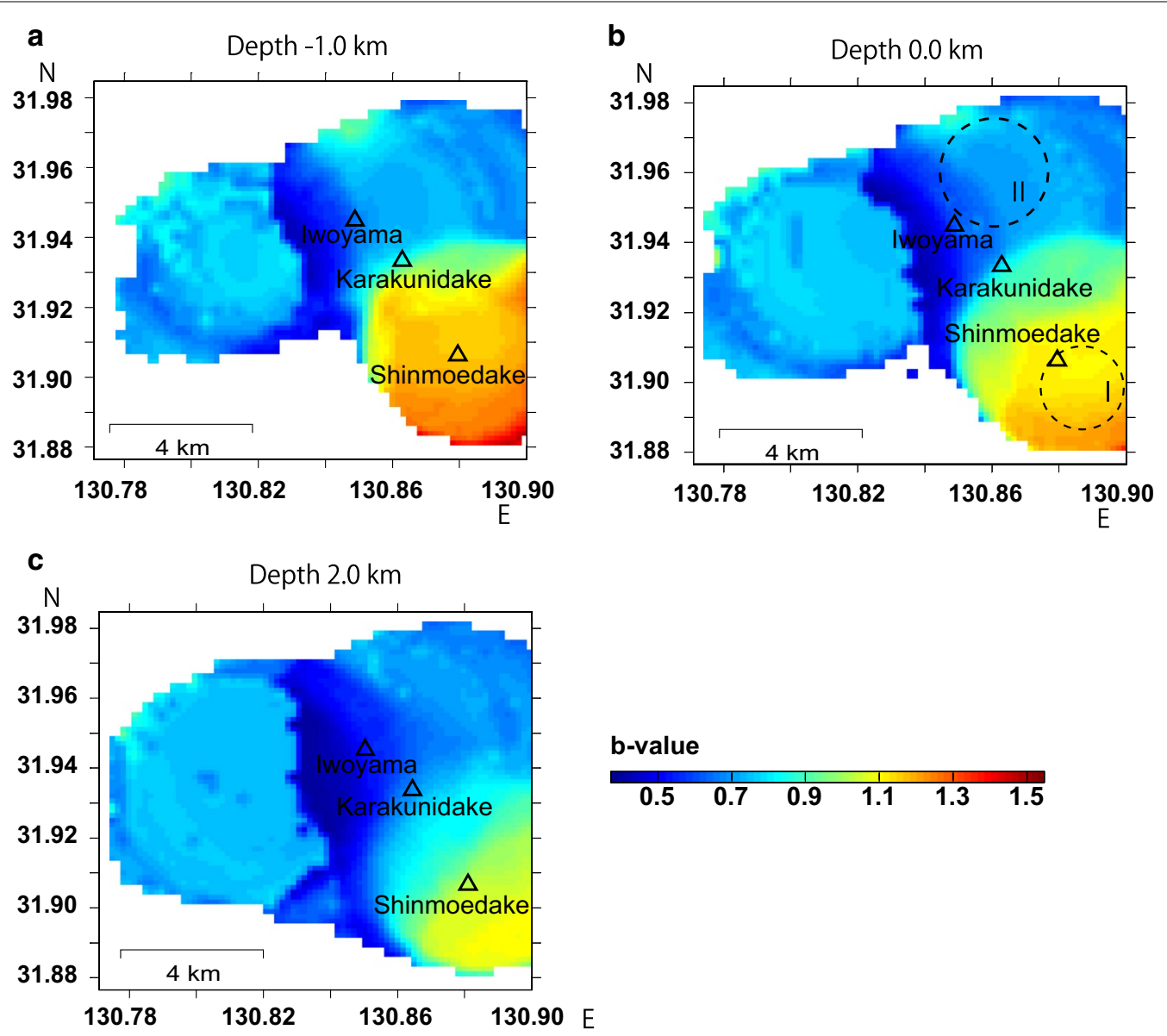

Fig. 2 Spatial distribution of $b$-values in the region indicated by the black dotted square in Fig. 1 at depths of $\mathbf{a}-1.0 \mathrm{~km}, \mathbf{b} 0.0 \mathrm{~km}$, and $\mathbf{c} 2.0 \mathrm{~km}$. The $b$-values of grids with spatial resolution coarser than $3.5 \mathrm{~km}$ are not shown. Black bold circles indicate regions where $p$ value analysis was performed

reported an interesting feature in hypocenter distributions in a region located 7.0-8.0 km northwest of the summit, with seismic activity in response to volcanic activity in and around Shinmoe-dake. Indeed, as for the 2017 eruption, activation of seismic activity in the region located 7.0-8.0 km northwest of the summit has been reported (JMA 2017). We therefore selected two regions, comprising events located at depths of -1.0 to $3.0 \mathrm{~km}$ beneath the summit (region A) and events at depths greater than $1.5 \mathrm{~km}$ at distances $7.0-8.0 \mathrm{~km}$ northwest of the summit (region B), to investigate temporal variations in $b$-values (Fig. 1). Region A approximately corresponds to the region of relatively high spatial $b$-values, but the previous analysis assumed constant $b$-values with respect to time. As a result, in region $A$ an increase in the $b$-value $(b=1.4)$ was observed beginning in early 2009 , followed by a subsequent decrease $(b=0.9)$ immediately before and during the 2011 eruption (Fig. 3a). Confidence limits were calculated by the method of Aki
(1965). We were not able to calculate the $b$-value time series since middle of 2016 in region A, since there are no longer enough events to calculate the time series. A similar trend in temporal $b$-value changes was observed in region A before the 2017 eruption (Fig. 3a), where the $b$-values increased from 2012 through 2015 and subsequently decreased from mid-2015. As shown in the spatial analysis of $b$-value distributions, which assumes no temporal changes in $b$-value, the $b$-value in region $\mathrm{A}$ is generally high relative to other regions in this study. These temporal changes are remarkable because they occur in response to volcanic activity in a region with a generally high background $b$-value.

Finally, we examined temporal changes in the $b$-value in the region located $7.0-8.0 \mathrm{~km}$ northwest of the summit (region B); however, we find that the temporal $b$-value errors in region $\mathrm{B}$ are large due to the low, variable seismicity rate (Fig. $3 \mathrm{~b}$ ). Thus, we divide the analytical period into four windows and calculate 

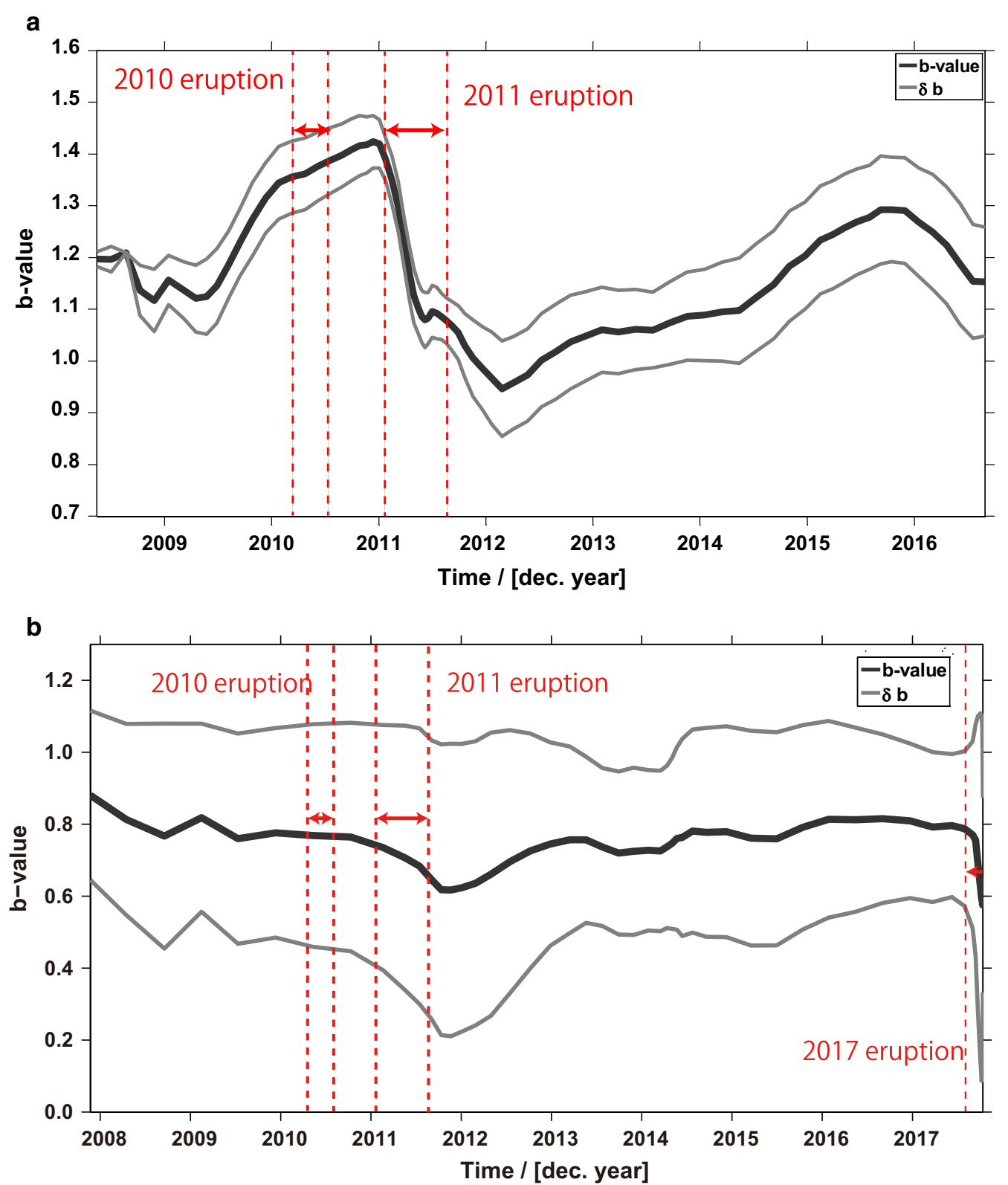

Fig. 3 Temporal distribution of $b$-values a beneath (region A) and $\mathbf{b}$ in the region 7.0-8.0 km northwest of the summit (region B). Gray lines show the standard deviation in the calculated $b$-values. Red broken lines indicate the start and end times of the 2010 and 2011 eruptions

a constant representative $b$-value for each window: before the 2011 eruption (period 1: January 1, 2007January 18, 2011); during and immediately after the 2011 eruption (period 2: January 19, 2011-December 31, 2011); before the 2017 eruption (period 3: January 1, 2012-September 30, 2017); and immediately before and during the 2017 eruption (period 4: October $1-26,2017)$. For simplicity, we describe periods 2 and 4 as during the 2011 and 2017 eruptions, respectively. Decreases in the $b$-value $(b=0.6)$ are found in region
B during periods 2 and 4, respectively (Fig. 4). We performed $p$-tests for the paired windows before and during both eruptions and found a $p$ value of $1.26 \times 10^{-8}$ for the periods before and during the 2011 eruption, and 0.0166 for the periods before and during the 2017 eruption. Thus, the probabilities that the periods before and during each eruption have the same true $b$-values can be rejected at the $98 \%$ confidence level. We therefore conclude that the temporal $b$-value changes related to these eruption sequences were real phenomena. 

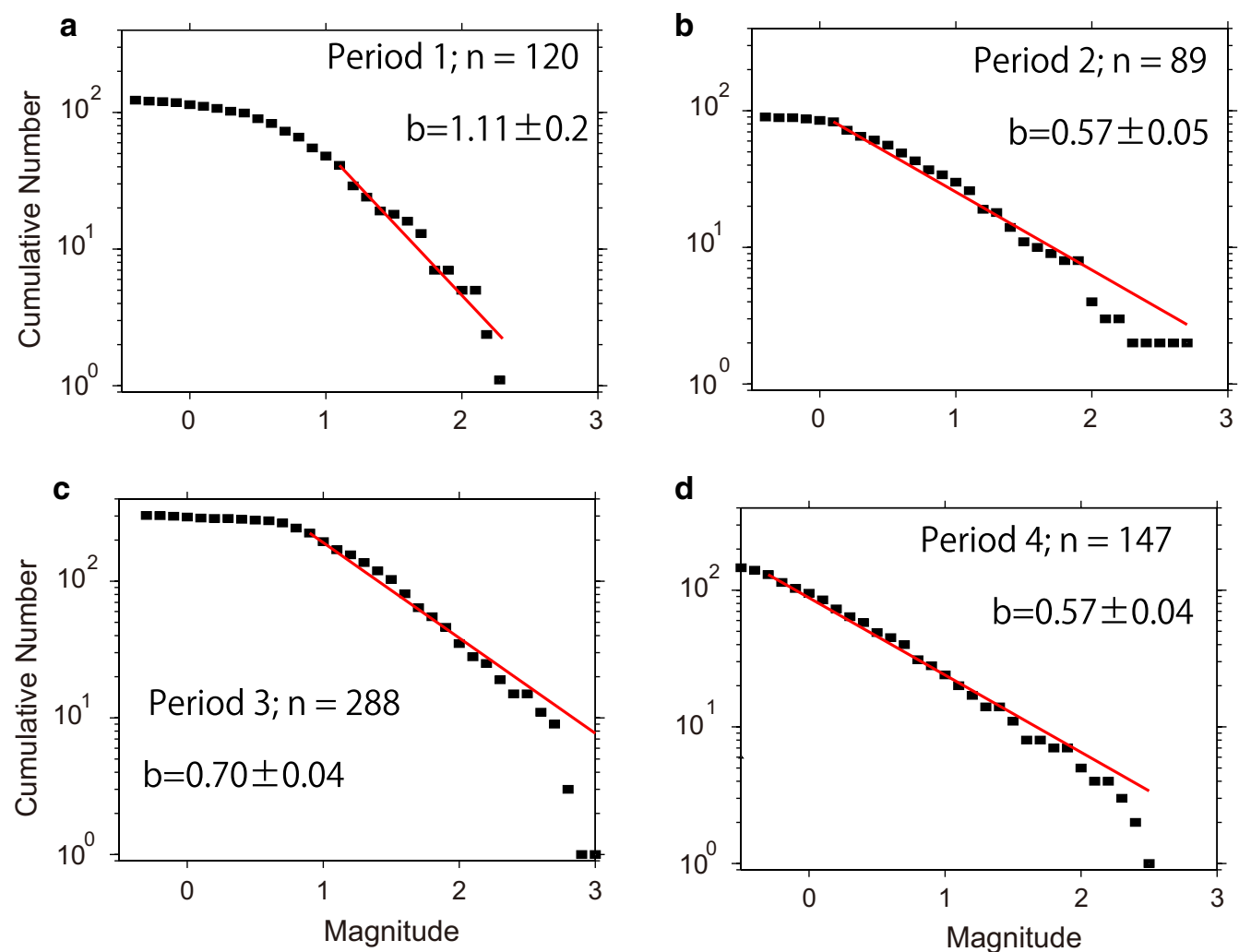

Fig. 4 b-values estimated in region B for each analysis window: before the 2011 eruption (period 1: January 1, 2007-January 18, 2011); during and immediately after the 2011 eruption (period 2: January 19, 2011-December 31, 2011); before the 2017 eruption (period 3: January 1, 2012September 30, 2017); and immediately before and during the 2017 eruption (period 4: October 1, 2017-October 26, 2017). The analyzed region is located 7.0-8.0 km northwest of the summit (region B). $n$ and $b$ in the figures indicate the number of events and representative $b$-values of each analysis period, respectively

\section{Discussion}

In this section, we discuss some potential causes of the relatively high $b$-value region and the temporal changes in $b$-values. At shallower depths, directly beneath the summit, the existence of pressure sources related to the 2011 eruption was reported by Takagi et al. (2011). Furthermore, an episode of volcanic tremor that occurred on October 9, 2017, two days before the 2017 eruption began, was located using a point-source approximation at a depth of $400 \mathrm{~m}$ a.s.l. beneath the summit with an estimated volumetric change of $1 \times 10^{4} \mathrm{~m}^{3}$ (ERI 2017). The region of relatively high $b$-value estimated in this study at shallower depths beneath the summit corresponds to the location of the pressure and tremor sources. This region of relatively high $b$-values is attributed to crustal heterogeneity caused by a dense network of cracks around these sources at shallow depths, as also inferred for other volcanoes (e.g., Wiemer and McNutt 1997; Wyss et al. 1997; Sanchez et al. 1998; Bridges and Gao 2006; Chiba et al. 2017).
Next, we consider the causes of the temporal changes in $b$-value. Many previous studies have reported temporal changes in $b$-values related to volcanic unrest (e.g., Gresta and Patanè 1983a, b; Patanè et al. 1992; Murru et al. 2007; Kato et al. 2015). For example, Kato et al. (2015) reported a temporal change in $b$-value a few days before the 2014 phreatic eruption of Mt. Ontake, Japan, which consisted of an increase in $b$-values, followed by a decrease. Their interpretation was that the high $b$-value reflected the increasing density of smaller faults and cracks due to the penetration of hot fluids, resulting in a reduction in effective normal stress (i.e., reduction in shear strength) on cracks and smaller faults, and a subsequent drop in $b$-value, as reflected by producing higher magnitude earthquakes due to the growth of small faults and cracks. Gresta and Patanè (1983a, b) reported significant increases and subsequent decreases in $b$-value before the 1981 and 1983 eruptions at Mt. Etna, Italy, and attributed the periods with high $b$-values during both eruptions to crustal heterogeneity and changes in 
the regional stress field related to the eruptions. Furthermore, Gresta and Patanè (1983b) pointed out that the changes in the stress field, rather than crustal heterogeneity, caused the increase in $b$-value. The remarkable differences between the high $b$-values (i.e., $b=3.03$ in 1981 vs. $b=1.45$ in 1983) cannot be explained in terms of differences in heterogeneity and rigidity of the crust.

We evaluate the temporal changes in the $b$-value beneath the summit (region A). An increase in the $b$-value was found in region A from the beginning of 2009 to immediately before the onset of the 2011 eruption (Fig. 3a); the 2010 phreatic eruption occurred during this period. Therefore, this increase is attributed to the increasing density of smaller faults and cracks due to the penetration of hot fluids related to the 2010 phreatic eruption and a resultant reduction in effective normal stress. The subsequent drop in the $b$-value occurred immediately before the onset of the 2011 eruption. We suggest that this decrease was generated by producing higher magnitude earthquakes due to the growth of a dense network of cracks related to the 2011 eruption in region A. Geospatial Information Authority of Japan (GSI) (2011) reported baseline length changes between stations across the summit and noticed an increase in the baseline length from the beginning of 2010 and an abrupt subsequent decrease during the 2011 eruption. It is interesting that the pattern of temporal changes in $b$-value related to the 2011 eruption is similar to that of the baseline length changes across Shinmoe-dake. Bearing this in mind, we also remark that the inferred change in crustal heterogeneity arose before and during the 2011 eruption. A similar interpretation can also be applied to the period before the 2017 eruption, which consisted of a gradual increase in $b$-value from 2012 through 2015 and a subsequent decrease from the beginning of 2016, although an eruption did not occur during this period. Of course, one possibility that must be considered is that the temporal changes in $b$-value in region A were generated by changes in the regional stress field related to volcanic activity in both time periods. However, we are unable to quantify the stress field changes, because most earthquakes were recorded by too few stations with impulsive arrivals and/or azimuthal gaps that are too large to allow focal mechanisms to be precisely constrained beneath the summit.

Next, we evaluate the decreases in $b$-values related to the 2011 and 2017 eruptions in the region $7.0-8.0 \mathrm{~km}$ northwest of the summit (region B). In region B, pressure sources that indicate the existence of a magma chamber were estimated at depths of $8.0-10.0 \mathrm{~km}$ by Nakao et al. (2013) and Ueda et al. (2013). Furthermore, it has been suggested from GNSS analysis that the 2017 eruption was a reactivation of the magma chamber related to the
2011 eruption (ERI 2017). Region B thus corresponds to the region above the magma chamber of the 2011 and 2017 eruptions and was therefore likely affected by the crustal heterogeneity generated by the crustal deformation associated with magmatic activity. We therefore propose that the decreases in $b$-value in region $\mathrm{B}$ were generated by producing higher magnitude earthquakes due to the growth of a dense network of cracks related to the 2011 and 2017 eruptions, similar to the decreases in $b$-values in region A. In addition to these considerations, it has been reported by JMA (2017) that the focal mechanisms of events in region $B$ changed slightly during the 2017 eruption. One possible reason for this change is that the stress field change due to the 2017 eruption also caused a decrease in the $b$-value of region B. As discussed above, Gresta and Patanè (1983b) pointed out that remarkable differences were observed between the high $b$-values of the 1981 and 1983 eruptions of Mt. Etna, which are attributed mainly to changes in the regional stress field acting at Mt. Etna associated with the volcanic eruptions. However, differences in the high $b$-values of region $\mathrm{B}$ in the present study $\left(b_{1}=1.11, b_{3}=0.70\right)$ were unremarkable. In addition to the high $b$-values associated with each eruption sequence, no difference was found between their low $b$-values $\left(b_{2}=b_{4}=0.57\right)$. Therefore, it is inferred that the decreases in $b$-value were generated by factors that include both crustal heterogeneity and stress changes related to volcanic activity in region $\mathrm{B}$, especially during period 4 (i.e., during the 2017 eruption).

The ability to meaningfully interpret $b$-value analysis provides important information about the causes of eruptions of Shinmoe-dake. We used only VT earthquakes in this study and described the overall features in terms of the spatial and temporal trends in $b$-value; however, it is expected that further physical properties of the magma plumbing system, which indirectly control eruptive activity in and around Shinmoe-dake, could be obtained by investigating the magnitude-frequency distributions of low-frequency earthquakes, tremor (Benoit et al. 2003), and explosive earthquakes (Nishimura et al. 2016), in addition to analysis of $b$-values of VT earthquakes. Such an approach from statistical seismology could become a useful tool for assessing the potential of activity in the near future, in and around Shinmoe-dake.

\section{Conclusions}

We investigated the spatial and temporal distributions of $b$-value to constrain the causes of volcanic activity and the magma plumbing system in and around Shinmoedake, Kirishima volcano, Japan, using the VT earthquake catalogue constructed by the JMA. A region of relatively high $b$-values $(b=1.5)$ was located at depths of -1.0 to 
$2.0 \mathrm{~km}$ beneath the summit. It is thus inferred that this region of relatively high $b$-value was generated by crustal heterogeneity related to pressure sources beneath the summit.

A temporal increase in $b$-value $(b=1.4)$ was observed beneath the summit from the beginning of 2009, followed by a decrease in the same region $(b=0.9)$ immediately before and during the 2011 eruption. These changes can be interpreted as the seismic consequences of the activation of small cracks near the magma chamber, resulting from the development of hydrothermal circulation related to the 2010 phreatic eruption, and the formation of cracks related to the 2011 eruption, which produces higher magnitude earthquakes, respectively. A similar interpretation can be applied to the increase and subsequent decrease in $b$-value before the 2017 eruption beneath the summit. Meanwhile, a decrease in $b$-value $(b=0.6)$ was found in the region located $7.0-8.0 \mathrm{~km}$ northwest of the summit during the 2011 and 2017 eruption sequences. This decrease likely reflects a combination of increased crack length due to the growth of small faults and cracks, and a change in the stress field near the magma chamber related to the 2011 and 2017 eruptions, which produces higher magnitude earthquakes.

\section{Additional file}

Additional file 1. Figure S1. Cummulative number of the original catalog events with all magnitude ranges located in the area indicated by the black square in Fig. 1, from August 1, 2002 through October 26, 2017. We used events that ocurred to the right of the dashed line, which correponds after January 1, 2007. Figure $\mathbf{S 2}$. $\mathbf{M}_{c}$ as a function of time for all catalog events in the area indicated by the black square in Fig. 1, from January 1, 2002 through October 26, 2017. We used events that ocurred to the right of the dashed line, which corresponds after January 1, 2007.

\section{Authors' contributions}

KC conducted the $b$-value analyses and drafted the manuscript. HS contributed to the data acquisition of the seismic catalog data and the interpretation of the results obtained in this study. Both authors read and approved the final manuscript.

\section{Acknowledgements}

We used volcanic observation data, including earthquake hypocenters, from Fukuoka District Meteorological Observatory, and employed the MATLAB software package ZMAP (Wiemer 2001). Figures were prepared using GMT (Wesel and Smith 1995). We thank the Editor Arthur Jolly and two anonymous reviewers for helping to improve the manuscript.

\section{Competing interests}

The authors declare that they have no competing interests.

\section{Availability of data and materials}

Please contact author for data requests.

\section{Funding}

This study was partially funded by the Institute of Seismology and Volcanology, Faculty of Science, Kyushu University.

\section{Publisher's Note}

Springer Nature remains neutral with regard to jurisdictional claims in published maps and institutional affiliations.

Received: 6 March 2018 Accepted: 13 July 2018

Published online: 23 July 2018

\section{References}

Aizawa K, Koyama T, Uyeshima M, Hase H, Hashimoto T, Kanda W, Yoshimura R, Utsugi M, Ogawa Y, Yamazaki K (2013) Magnetotelluric and temperature monitoring after the 2011 sub-Plinian eruptions of Shinmoe-dake volcano. Earth Planets Space 65(6):539-550

Aki K (1965) Maximum likelihood estimate of $b$ in the formula $\log N=a-b M$ and its confidence limits. Bull Earthq Res Inst Tokyo Univ 43:237-239

Benoit JP, McNutt SR, Barboza V (2003) Duration-amplitude distribution of volcanic tremor. J Geophys Res 108(B3):2145. https://doi.org/10.1029/2001J B001520

Bridges DL, Gao SS (2006) Spatial variation of seismic b-values beneath Makushin Volcano, Unalaska Island, Alaska. Earth Planet Sci Lett 245:408-415. https:// doi.org/10.1016/j.epsl.2006.03.010

Chiba K, Ueda H, Tanada T (2017) Relationship between b-value distribution and the magma plumbing system in and around Mt. Tarumae, Japan. J Disaster Res 12:932-943

Earthquake Research Institute, The University of Tokyo (2017) Report of coordinating committee for prediction of volcano eruption, 1-27 (in Japanese)

Farrell J, Smith RB (2009) Earthquake swarm and b-value characterization of the Yellowstone volcano-tectonic system. J Volcanol Geotherm Res 188:260-276

Frohlich C, Davis S (1993) Teleseismic b-values: or much ado about 1.0. J Geophys Res 98:631-644

Geospatial Information Authority of Japan (2011) Report of coordinating committee for prediction of volcano eruption. 108, 197-220 (in Japanese)

Gresta S, Patanè G (1983a) Variation of $b$ values before the Etnean eruption of March 1981. Pure Appl Geophys 121:287-295

Gresta S, Patanè G (1983b) Changes in b values before the Etnean eruption of March-August 1983. Pure Appl Geophys 121:903-912

Gutenberg B, Richter CF (1944) Frequency of earthquakes in California. Bull Seismol Soc Am 34:185-188

Imura R, Kobayashi T (1991) Eruptions of Shinmoedake volcano, Kirishima volcano group, in the last 300 years. Bull Volc Soc Jpn (kazan) 36:135-148 (in Japanese)

Ishimoto M, lida K (1939) Observations sur les seisms enregistre par le microseismograph construit demiement. Bull Earthq Res Inst Tokyo Univ 17:443-478

Japan Meteorological Agency (2017) Report of coordinating committee for prediction of volcano eruption, 1-54 (in Japanese)

Japan Meteorological Agency. http://www.data.jma.go.jp/svd/vois/data/fukuo ka/505_Kirishimayama/505_history.html

Kato A, Terakawa T, Yamanaka Y, Maeda Y, Horikawa S, Matsuhiro K, Okuda T (2015) Preparatory and precursory processes leading up to the 2014 phreatic eruption of Mount Ontake, Japan. Earth Planets Space 67:111

McNutt SR (2005) Volcanic seismology Annu. Rev Earth Planet Sci 32:461-491

Mogi K (1962) Magnitude-frequency relation for elastic shocks accompanying fractures of various materials and some related problems in earthquakes. Bull Earthq Res Inst 40:831-853

Murru M, Console R, Falcone G, Montuori C, Sgroi T (2007) Spatial mapping of the $b$ value at Mt. Etna, Italy using earthquakes data recorded from 1999 to 2005. J Geophys Res 112:B12303

Nakao S, Morita Y, Yakiwara H, Oikawa J, Ueda H, Takahashi H, Ohta Y, Matsushima T, Iguchi M (2013) Volume change of the magma reservoir relating to the 2011 Kirishima Shinmoe-dake eruption — charging, discharging and recharging process inferred frm GPS measurements. Earth Planets Space 65:505-515. https://doi.org/10.5047/eps.2013.05.017

National Institute of Advanced Industrial Science and Technology (2017) Report of coordinating committee for prediction of volcano eruption, 1-9 (in Japanese) 
Nishimura T, Iguchi M, Hendrasto M, Aoyama M, Yamada T, Ripepe M, Genco R (2016) Magnitude-frequency distribution of volcanic explosion earthquakes. Earth Planets Space 68:125. https://doi.org/10.1186/s40623-016-0505-2 Patanè D, Caltabiano T, Del Pezzo E, Gresta S (1992) Time variation of $b$ and $Q_{c}$ at Mt. Etna (1981-1987). Phys Earth Planet Int 71:137-140

Sanchez JJ, McNutt SR, Wyss M (1998) Temporal and three dimensional spatial analysis of the frequency-magnitude distribution near Long Valley Caldera, California. Geophys J Int 134:409-421

Scholz CH (1968) The frequency-magnitude relation of microfracturing in rock and its relation to earthquake. Bull Seis Soc Am 58:399-415

Takagi A, Fukui K, Onizawa S, Yamamoto T, Kato K, Chikazawa S, Fujiwara K, Sakai T (2011) Ground deformation around the shimoe crater before the 2011 Kirishima eruption. Abstract of Fall Meeting Volcanological Society of Japan 119 (in Japanese)

Ueda H, Kozono T, Fujita E, Kohno Y, Nagai M, Miyagi Y, Tanada T (2013) Crustal deformation associated with the 2011 Shinmoe-dake eruption as observed by tiltmeters and GPS. Earth Planets Space 65:517-525. https://doi. org/10.5047/eps.2013.03.001

Urbancic TI, Trifu Cl, Long JM, Young RP (1992) Space-time correlations of b values with stress release. PAGEOPH 139:449-462

Utsu T (1992) On seismicity. Report of the Joint Research Institute for Statistical Mathematics. Inst Stat Math Tokyo 34:139-157

Warren NW, Latham GV (1970) An experimental study of thermally induced microfracturing and its relation to volcanic seismicity. J Geophys Res 75:4455-4464
Wesel P, Smith WHF (1995) New version of the generic mapping tools released. EOS Trans AGU 76:329. https://doi.org/10.1029/95EO00198

Wiemer S (2001) A software package to analyze seismicity: ZMAP. Seismol Res Lett 72(3):373-382

Wiemer S, Benoit J (1996) Mapping the b-value anomaly at $100 \mathrm{~km}$ depth in the Alaska and New Zealand subduction zones. Geophys Res Lett 23:1557-1560

Wiemer S, McNutt SR (1997) Variations in the frequency-magnitude distribution with depth in two volcanic areas: Mount St. Helens, Washington, and Mt. Spurr, Alaska. Geophys Res Lett 24:189-192

Wiemer S, Wyss M (2000) Minimum magnitude of completeness in earthquake catalogs: examples from Alaska, the Western United States, and Japan. Bull Seismol Soc Am 90:859-869

Wiemer S, Wyss M (2002) Mapping spatial variability of the frequencymagnitude distribution of earthquakes. In: Dmowska R, Saltzman B (eds) Advances in geophysics, vol 45. Elsevier, USA

Wiemer S, McNutt SR, Wyss M (1998) Temporal and three-dimensional spatial analysis of the frequency-magnitude distribution near Long Valley caldera, California. Geophys J Int 134:409-421

Wyss M (1973) Towards a physical understanding of the earthquake frequency distribution. Geophys J R Astr 31:341-359

Wyss M, Shimazaki K, Wiemer S (1997) Mapping active magma chambers by $b$ values beneath the off-Ito volcano, Japan. J Geophys Res 102:20413-20422

\section{Submit your manuscript to a SpringerOpen ${ }^{\odot}$ journal and benefit from:}

- Convenient online submission

- Rigorous peer review

- Open access: articles freely available online

- High visibility within the field

- Retaining the copyright to your article

Submit your next manuscript at $\boldsymbol{\nabla}$ springeropen.com 